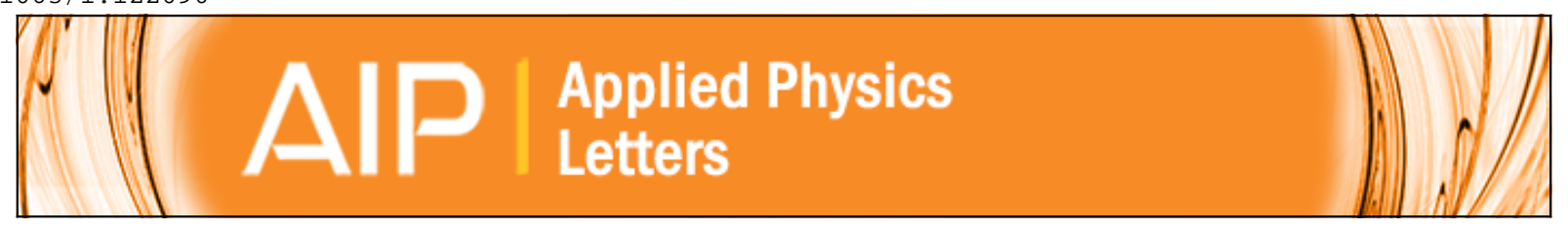

Properties of $\mathrm{Ba}(\mathrm{Mg} \mathrm{1/3} \mathrm{Ta} 2 / 3) 03$ thin films prepared by metalorganic solution deposition technique for microwave applications

P. C. Joshi and S. B. Desu

Citation: Applied Physics Letters 73, 1080 (1998); doi: 10.1063/1.122090

View online: http://dx.doi.org/10.1063/1.122090

View Table of Contents: http://scitation.aip.org/content/aip/journal/apl/73/8?ver=pdfcov

Published by the AIP Publishing 


\title{
Properties of $\mathrm{Ba}\left(\mathrm{Mg}_{1 / 3} \mathrm{Ta}_{2 / 3}\right) \mathrm{O}_{3}$ thin films prepared by metalorganic solution deposition technique for microwave applications
}

\author{
P. C. Joshi and S. B. Desu \\ Department of Materials Science and Engineering, Virginia Tech, Blacksburg, Virginia 24061-0237
}

(Received 10 March 1998; accepted for publication 29 May 1998)

\begin{abstract}
We report on the properties of $\mathrm{Ba}\left(\mathrm{Mg}_{1 / 3} \mathrm{Ta}_{2 / 3}\right) \mathrm{O}_{3}$ thin films prepared by the metalorganic solution deposition technique. Bulk $\mathrm{Ba}\left(\mathrm{Mg}_{1 / 3} \mathrm{Ta}_{2 / 3}\right) \mathrm{O}_{3}$ ceramics have shown excellent dielectric properties at microwave frequencies; however, the high sintering temperature of bulk material is the major obstacle in their use as dielectric resonators to miniaturize microwave circuits. It was possible to obtain an ordered-perovskite phase of $0.3-\mu$ m-thick $\mathrm{Ba}\left(\mathrm{Mg}_{1 / 3} \mathrm{Ta}_{2 / 3}\right) \mathrm{O}_{3}$ films with trigonal symmetry at an annealing temperature of $700{ }^{\circ} \mathrm{C}$, which is much lower than the bulk sintering temperatures. The electrical measurements were conducted on $\mathrm{Pt} / \mathrm{Ba}\left(\mathrm{Mg}_{1 / 3} \mathrm{Ta}_{2 / 3}\right) \mathrm{O}_{3} / \mathrm{Pt}$ capacitors. The typical measured small signal dielectric constant and dissipation factor at $100 \mathrm{kHz}$ were 22.2 and 0.009 , respectively. The dielectric constant of thin films was comparable to the typical values $\left(\epsilon_{r}\right.$ $\sim 23.5-25$ ) reported for bulk ceramics. The temperature coefficient of capacitance was -145 $\mathrm{ppm} /{ }^{\circ} \mathrm{C}$ in the measured temperature range of $25-125^{\circ} \mathrm{C}$. The leakage current density was lower than $10^{-7} \mathrm{~A} / \mathrm{cm}^{2}$ at an applied electric field of $0.5 \mathrm{MV} / \mathrm{cm}$. The high dielectric constant, which is comparable to bulk, low dielectric loss, and good temperature and bias stability suggest the suitability of $\mathrm{Ba}\left(\mathrm{Mg}_{1 / 3} \mathrm{Ta}_{2 / 3}\right) \mathrm{O}_{3}$ thin films for microwave communications and integrated capacitor applications. (C) 1998 American Institute of Physics. [S0003-6951(98)01931-7]
\end{abstract}

There is currently an explosive growth in the need for, and application of, microwave circuit technologies. The progress in microwave communication applications and continuing miniaturization of integrated circuitry has resulted in a demand for smaller microwave resonators, which are a key component in microwave circuits. ${ }^{1}$ Dielectric materials which can be used as resonators must exhibit a high dielectric constant $\epsilon_{r}$ (the size of the dielectric resonator is proportional to $1 / \sqrt{\epsilon_{r}}$ ), extremely low dielectric loss (high $Q, Q$ is given by $1 / \tan \delta$ ), and small temperature coefficient of resonant frequency. Complex perovskite materials with the chemical formula $\mathrm{Ba}\left(B_{1 / 3} B^{\prime}{ }_{2 / 3}\right) \mathrm{O}_{3}\left(B=\mathrm{Mg}, \mathrm{Zn} ; B^{\prime}=\mathrm{Ta}\right.$, $\mathrm{Nb})$ have been reported to possess excellent microwave properties. $^{2-4}$ In particular, $\mathrm{Ba}\left(\mathrm{Mg}_{1 / 3} \mathrm{Ta}_{2 / 3}\right) \mathrm{O}_{3}$ (BMT) has been reported to show a dielectric constant $\epsilon_{r}$ of $25, Q$ value of 36000 at $10 \mathrm{GHz}$, and a low temperature coefficient of resonant frequency of $4.4 \mathrm{ppm} /{ }^{\circ} \mathrm{C}^{5-7}$ However, poor sinterability and high densification temperature are the major problems to be solved to exploit the excellent properties of bulk BMT ceramics in microwave devices. The bulk ceramics prepared by conventional solid state reaction method with addition of various sintering aids require extremely high sintering temperature $\left(\geqslant 1600^{\circ} \mathrm{C}\right)$ or very long sintering time at lower temperatures $\left(\sim 100 \mathrm{~h}\right.$ at $\left.1450{ }^{\circ} \mathrm{C}\right)$. Attempts have also been made to reduce the processing temperature by using modified solid state reaction method, rapid heating, and solgel method. ${ }^{4-9}$ A reduction in sintering temperature of BMT is necessary for use as a dielectric resonator in miniaturized communication devices. In the present work, we have fabricated the thin films of $\mathrm{Ba}\left(\mathrm{Mg}_{1 / 3} \mathrm{Ta}_{2 / 3}\right) \mathrm{O}_{3}$ for applications in microwave frequency communications devices. Thin films of dielectric materials offer the advantage, in general, of much lower crystallization temperatures and larger capacitance than bulk samples and can be integrated in microelectronics devices.

Thin films of $\mathrm{Ba}\left(\mathrm{Mg}_{1 / 3} \mathrm{Ta}_{2 / 3}\right) \mathrm{O}_{3}$ were prepared by metalorganic solution deposition (MOSD) technique. MOSD processing has been extensively used in thin film technology because of the advantages of low processing temperature, precise composition control, low equipment cost, and uniform deposition over large area substrates. ${ }^{10}$ Thin films of BMT were fabricated using barium acetate, magnesium methoxide, and tantalum ethoxide as precursors. Acetic acid and 2-methoxyethanol were selected as solvents. In the experiment, barium acetate was initially dissolved in acetic acid under room temperature conditions. The clear solution thus formed was added to the solution of tantalum ethoxide and magnesium methoxide in 2-methoxyethanol to prepare a stoichiometric, clear, and stable $\mathrm{Ba}\left(\mathrm{Mg}_{1 / 3} \mathrm{Ta}_{2 / 3}\right) \mathrm{O}_{3}$ precursor solution. The viscosity of the solution was controlled by varying the 2-methoxyethanol content. Dust and other suspended impurities were removed from the solution by filtering through $0.2 \mu \mathrm{m}$ syringe filters. The precursor films were coated on to Pt-coated Si substrates by spin coating using a photoresist spinner. The thickness of the films was controlled by adjusting the viscosity of the solution and spin speed. After spinning on to various substrates, films were kept on a hot plate (at $\sim 350{ }^{\circ} \mathrm{C}$ ) in air for $10 \mathrm{~min}$. This step was repeated after each coating to ensure complete removal of volatile matter. The postdeposition annealing of the films was carried out at various temperatures in an oxygen atmosphere. In the present letter, we report the structural and electrical properties of $\mathrm{Ba}\left(\mathrm{Mg}_{1 / 3} \mathrm{Ta}_{2 / 3}\right) \mathrm{O}_{3}$ thin films. The crystallinity of the films was analyzed by $\mathrm{x}$-ray diffraction (XRD). The microstructure of the films was analyzed by atomic force microscopy (AFM). The electrical properties reported in- 


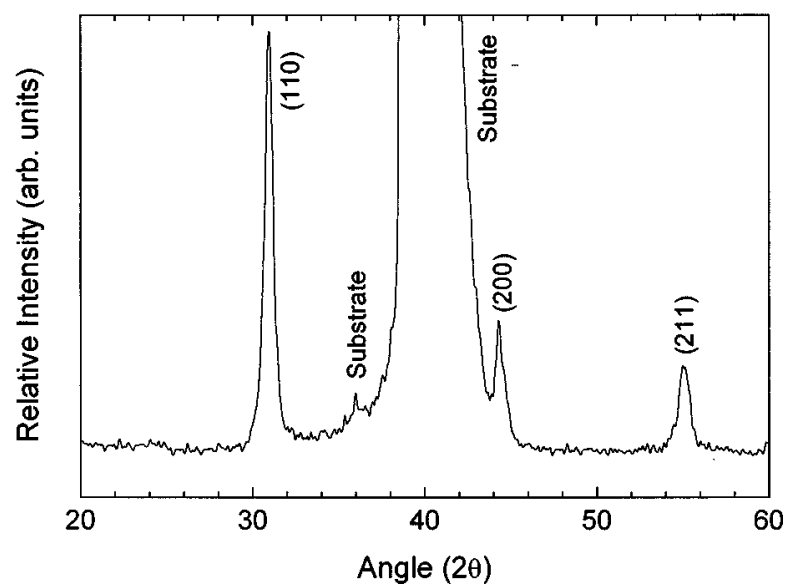

FIG. 1. X-ray diffraction pattern of $\mathrm{Ba}\left(\mathrm{Mg}_{1 / 3} \mathrm{Ta}_{2 / 3}\right) \mathrm{O}_{3}$ thin film annealed at $700{ }^{\circ} \mathrm{C}$ for $60 \mathrm{~min}$.

clude dielectric, current density-electric field $(J-E)$, and capacitance-voltage $(C-V)$.

The pyrolyzed films (at $\sim 350^{\circ} \mathrm{C}$ ) were found to be amorphous and postdeposition annealing was required to develop crystallinity. The structure of the films was analyzed by Scintag XDS 2000 diffractometer using $\mathrm{Cu} \mathrm{K} \alpha$ radiation at $40 \mathrm{kV}$. Figure 1 shows the XRD patterns of films annealed at $700{ }^{\circ} \mathrm{C}$ for $60 \mathrm{~min}$. It was possible to attain a well-crystallized perovskite phase at $700{ }^{\circ} \mathrm{C}$ with peaks attributable to trigonal phase. The XRD patterns also revealed that films were polycrystalline in nature with no evidence of preferred orientation or secondary phases. The broad XRD peaks indicated the presence of small grains. $\mathrm{Ba}\left(\mathrm{Mg}_{1 / 3} \mathrm{Ta}_{2 / 3}\right) \mathrm{O}_{3}$ is a disorder-order perovskite-type oxide compound. ${ }^{11}$ The ordered compounds with the general formula $\mathrm{Ba}\left(B_{1 / 3} B_{2 / 3}^{\prime}\right) \mathrm{O}_{3}\left(B=\mathrm{Mg}, \mathrm{Zn} ; B^{\prime}=\mathrm{Ta}, \mathrm{Nb}\right)$ adopt a trigonal symmetry owing to a rhombohedral distortion along a $\langle 111\rangle$ direction of the cubic cell. The trigonal symmetry is $P \overline{3} m 1$ and the ordered compounds are indexed in terms of hexagonal unit cell. The significantly lower processing temperature of BMT thin films compared to bulk sintering temperature show the possibility of exploiting thin films for microwave devices. The surface morphology of $\mathrm{Ba}\left(\mathrm{Mg}_{1 / 3} \mathrm{Ta}_{2 / 3}\right) \mathrm{O}_{3}$ thin films was analyzed by Digital Instrument's Dimension 3000 atomic force microscope using tapping mode with amplitude modulation. The surface morphology of the films was smooth with no cracks and defects, as shown in Fig. 2, and the average surface roughness was less than $4 \mathrm{~nm}$. The films exhibited a dense microstructure and the grain size was very fine.

The dielectric properties of $\mathrm{Ba}\left(\mathrm{Mg}_{1 / 3} \mathrm{Ta}_{2 / 3}\right) \mathrm{O}_{3}$ thin films were analyzed in terms of the dielectric constant $\epsilon_{r}$ and dissipation factor $\tan \delta$. The dielectric measurements were conducted on metal-insulator-metal (MIM) capacitors with an HP 4192A impedance analyzer. Several platinum electrodes $\left(\right.$ area $\left.=3.7 \times 10^{-4} \mathrm{~cm}^{2}\right)$ were sputter deposited through a shadow mask on the top surface of the films to form MIM capacitors. Figure 3 shows the dielectric constant and dissipation factor as a function of frequency for a $0.3-\mu \mathrm{m}$-thick film annealed at $700{ }^{\circ} \mathrm{C}$. The small signal dielectric constant and dissipation factor at a frequency of $100 \mathrm{kHz}$ were 22.2 and 0.009 , respectively. The dielectric constant of thin films

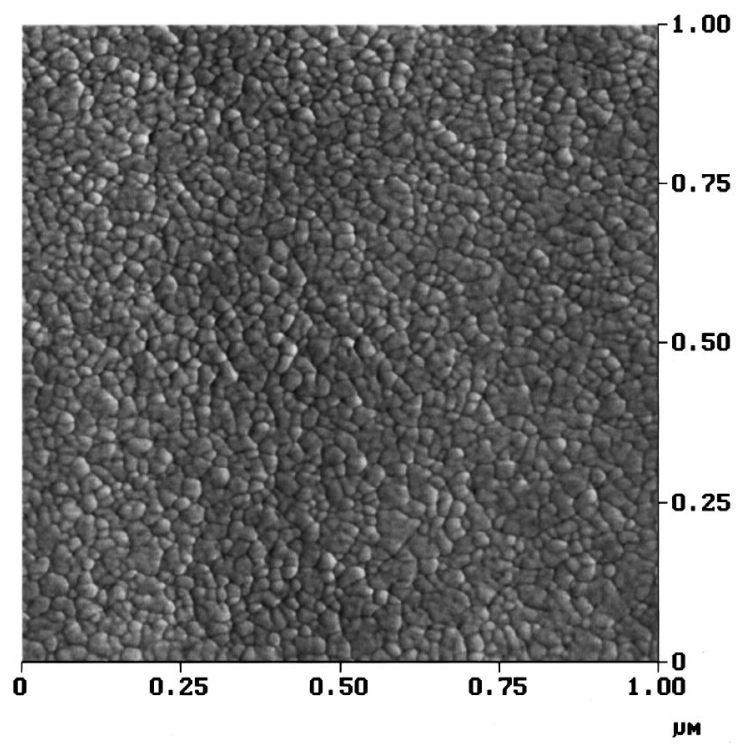

FIG. 2. Atomic force micrograph of $\mathrm{Ba}\left(\mathrm{Mg}_{1 / 3} \mathrm{Ta}_{2 / 3}\right) \mathrm{O}_{3}$ thin film annealed at $700{ }^{\circ} \mathrm{C}$ for $60 \mathrm{~min}$.

was comparable to the value $\left(\epsilon_{r} \sim 23.5-25\right)$ reported for bulk BMT ceramics. ${ }^{5-9,12}$ The intrinsic dissipation factor value is expected to be even lower than 0.009 as the effects of series and parallel resistances due to measurement configuration on the measured values of capacitance and loss factor were not modeled. The dielectric properties did not show any appreciable dispersion with frequency up to about $1 \mathrm{MHz}$ indicating good film/electrode interfacial characteristics. However, as the frequency was increased above $1 \mathrm{MHz}$, the dielectric constant was found to decrease and the loss factor was found to increase with frequency. This behavior was found to be extrinsic in nature as similar behavior was observed at around the same frequency for thin films of other dielectric materials. At frequencies of the order of a few megahertz, the stray inductance $L$ of the contacts and wires and/or the presence of a finite resistance in series with the film, which may arise due to intrinsic or extrinsic sources, may cause such behavior. ${ }^{13,14}$

The thermal stability of MIM capacitors was analyzed in the temperature range of $25-125^{\circ} \mathrm{C}$. The temperature stability of the capacitance was measured in terms of the parameter $\Delta C / C_{0}$, where $\Delta C$ is the change in capacitance relative

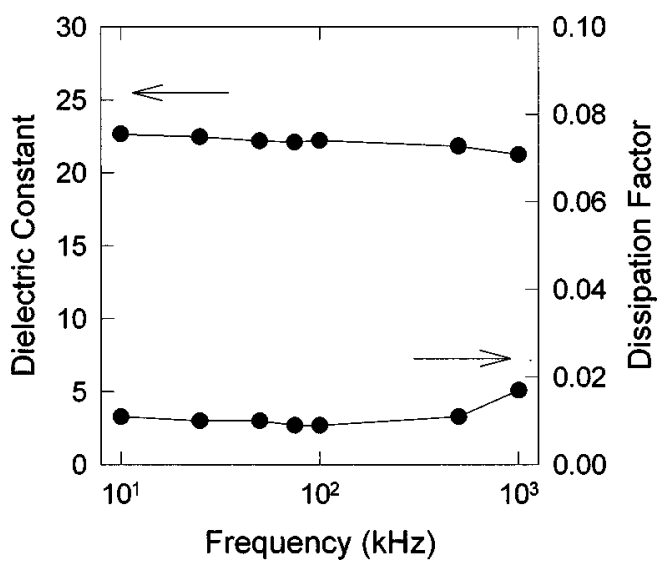

FIG. 3. Dielectric constant and dissipation factor of 0.3 - $\mu \mathrm{m}$-thick $\mathrm{Ba}\left(\mathrm{Mg}_{1 / 3} \mathrm{Ta}_{2 / 2}\right) \mathrm{O}_{3}$ film as a function of frequency. 


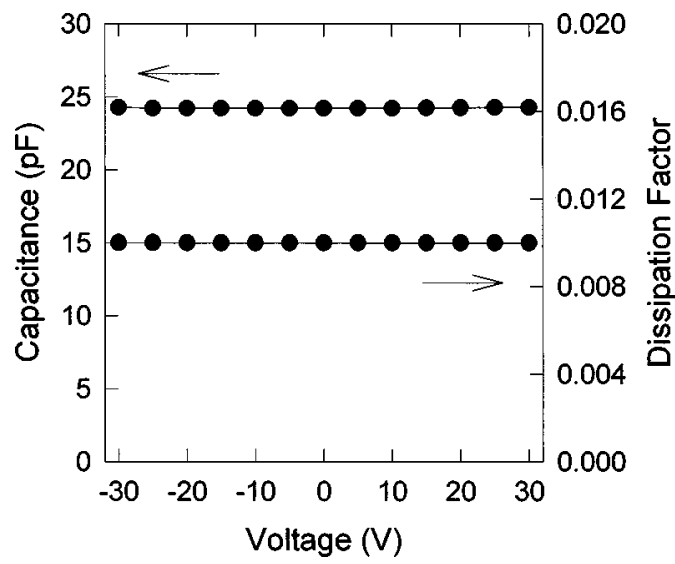

FIG. 4. Bias dependence of the capacitance and dissipation factor of $\mathrm{Ba}\left(\mathrm{Mg}_{1 / 3} \mathrm{Ta}_{2 / 3}\right) \mathrm{O}_{3}$ thin film.

to the capacitance $C_{0}$ at $25^{\circ} \mathrm{C}$. The change in film capacitance relative to film capacitance at $25^{\circ} \mathrm{C}$ was found to be lower than $1.5 \%$ up to $125^{\circ} \mathrm{C}$ indicating good temperature stability of BMT-based thin film capacitors. The loss factor was found to increase from 0.009 to 0.015 as the temperature was increased from 25 to $125^{\circ} \mathrm{C}$. The BMT thin films exhibited a negative temperature coefficient of capacitance of $-145 \mathrm{ppm} /{ }^{\circ} \mathrm{C}$ in the measured temperature range of $25-$ $125{ }^{\circ} \mathrm{C}$ which is comparable to the value reported for bulk material. ${ }^{15}$ The high dielectric constant, low dielectric loss, and good thermal stability characteristics show the suitability of $\mathrm{Ba}\left(\mathrm{Mg}_{1 / 3} \mathrm{Ta}_{2 / 3}\right) \mathrm{O}_{3}$ thin films for integrated microwave devices.

The bias stability of MIM capacitors was analyzed in terms of capacitance-voltage $(C-V)$ and leakage current characteristics to establish their reliability for capacitor applications. The $C-V$ measurements were conducted on MIM capacitors by applying a small ac signal of $10 \mathrm{mV}$ amplitude and $100 \mathrm{kHz}$ frequency across the sample while the dc electric field was swept from a positive bias to negative bias and back again. Figure 4 shows the $C-V$ characteristics of BMT thin films in MIM configuration. The capacitance and dissipation factor did not show appreciable dependence on the bias voltage. The change in film capacitance was found to be less than $0.3 \%$ up to an applied voltage of $30 \mathrm{~V}$, corresponding to a field of $1 \mathrm{MV} / \mathrm{cm}$ across the sample, indicating good field stability. The insulating properties of BMT thin films were analyzed in terms of leakage current density versus electric field $(J-E)$ characteristics. The $J-E$ characteristics, as shown in Fig. 5, were measured using HP 4140B test system by applying dc voltage with a step height of $1 \mathrm{~V}$ and a delay time of $30 \mathrm{~s}$. The leakage current density of the films was lower than $10^{-7} \mathrm{~A} / \mathrm{cm}^{2}$ up to an applied electric field of $0.5 \mathrm{MV} / \mathrm{cm}$, indicating good insulating characteristics. The small change in capacitance with bias up to an applied electric field of $1 \mathrm{MV} / \mathrm{cm}$ and low leakage current density establish good insulating characteristics of $\mathrm{Ba}\left(\mathrm{Mg}_{1 / 3} \mathrm{Ta}_{2 / 3}\right) \mathrm{O}_{3}$ thin films and suggest their suitability for integrated capacitor applications.

In conclusion, $\mathrm{Ba}\left(\mathrm{Mg}_{1 / 3} \mathrm{Ta}_{2 / 3}\right) \mathrm{O}_{3}$ thin films with crystalline structure were successfully prepared by metalorganic solution deposition technique on Pt-coated Si substrates at a temperature much lower than the bulk sintering tempera-

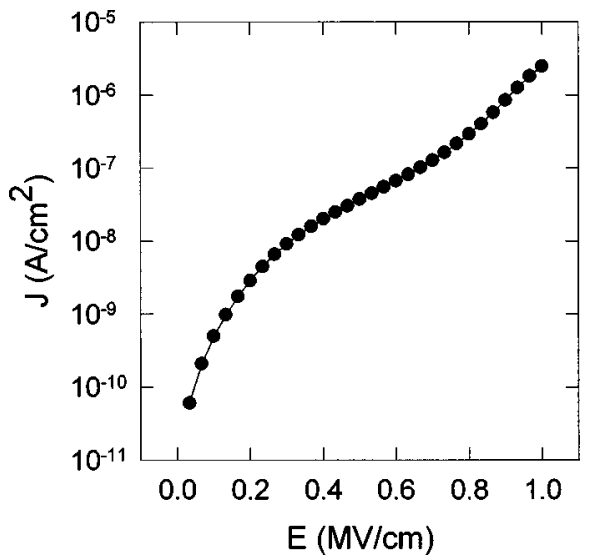

FIG. 5. $J-E$ characteristics of $0.3-\mu$ m-thick $\mathrm{Ba}\left(\mathrm{Mg}_{1 / 3} \mathrm{Ta}_{2 / 3}\right) \mathrm{O}_{3}$ films annealed at $700{ }^{\circ} \mathrm{C}$.

tures. The films were found to be well crystallized in ordered perovskite phase with trigonal symmetry at an annealing temperature of $700{ }^{\circ} \mathrm{C}$. The surface morphology of the films was smooth with no cracks or defects and the grain size was fine. The measured small signal dielectric constant and dissipation factor at $100 \mathrm{kHz}$ were 22.2 and 0.009 , respectively. The dielectric constant of thin films was comparable to the values $\left(\epsilon_{r} \sim 23.5-25\right)$ reported for bulk ceramics. The MIM capacitors exhibited good temperature and bias stability. The temperature coefficient of capacitance was $-145 \mathrm{ppm} /{ }^{\circ} \mathrm{C}$ in the measured temperature range of $25-125^{\circ} \mathrm{C}$. The film capacitance showed less than $0.3 \%$ change up to an applied electric field of $1 \mathrm{MV} / \mathrm{cm}$ across the sample. The leakage current density was lower than $10^{-7} \mathrm{~A} / \mathrm{cm}^{2}$ at an applied electric field of $0.5 \mathrm{MV} / \mathrm{cm}$. The high dielectric constant, which is comparable to bulk, much lower processing temperature compared to bulk sintering temperature, low dielectric loss, and good temperature and bias stability characteristics suggest the suitability of $\mathrm{Ba}\left(\mathrm{Mg}_{1 / 3} \mathrm{Ta}_{2 / 3}\right) \mathrm{O}_{3}$ thin films for microwave and integrated capacitor applications.

${ }^{1}$ A. J. Moulson and J. M. Herbert, Electroceramics (Chapman and Hall, New York, 1990).

${ }^{2}$ M. Furuya and A. Ochi, Jpn. J. Appl. Phys., Part 1 33, 5482 (1994).

${ }^{3}$ S. Kawashima, M. Nishida, I. Ueda, and H. Ouchi, J. Am. Ceram. Soc. 66, 421 (1983).

${ }^{4}$ T. Fukui, C. Sakurai, and M. Okuyama, J. Mater. Res. 7, 1883 (1992).

${ }^{5} \mathrm{~K}$. Matsumoto, T. Hiuga, K. Takada, and H. Ichimura, in Proceedings of the 6th IEEE International Symposium on Applications of Ferroelectrics (Bethlehem, PA, 1986), pp. 118-121.

${ }^{6}$ H. Matsumoto, H. Tamura, and K. Wakino, Jpn. J. Appl. Phys., Part 130 , 2347 (1991).

${ }^{7}$ X. M. Chen and Y. J. Wu, J. Mater. Sci.: Mater. Electron. 7, 369 (1996).

${ }^{8}$ M. Sugiyama, T. Inuzuka, and H. Kubo, Ceram. Trans. 15, 153 (1990).

${ }^{9}$ S. Katayama, I. Yoshinaga, N. Yamada, and T. Nagai, J. Am. Ceram. Soc. 79, 2059 (1996).

${ }^{10}$ L. C. Klein, Sol-Gel Technology for Thin Film, Fibers, Preforms, Electronics and Specialty Shapes (Noyes, Park Ridge, NJ, 1988).

${ }^{11}$ D. J. Babber, K. M. Moulding, J. Zhou, and M. Li, J. Mater. Sci. 32, 1531 (1997).

${ }^{12}$ O. Renoult, J. P. Boilot, F. Chaput, R. Papiernik, L. G. H. Pfalzgraf, and M. Lejeune, J. Am. Ceram. Soc. 75, 3337 (1992).

${ }^{13}$ P. C. Joshi and S. B. Desu, J. Appl. Phys. 80, 2349 (1996).

${ }^{14}$ M. Sayer, A. Mansingh, A. K. Arora, and A. Lo, Integr. Ferroelectr. 1, 129 (1992).

${ }^{15}$ T Nagai. M Sugiyama, M. Sando, and K. Niihara, Ipn. J. Appl. Phys Part 1 35, 5163 (1996). 